\title{
O sentido de participação nas escolas públicas estaduais do município de Assu/ RN: possibilidade de construção democrática
}

\author{
Maria da Conceição Fonseca ${ }^{1}$ \\ https://orcid.org/0000-0002-2373-0685 \\ Arilene Maria Soares de Medeiros ${ }^{2}$ \\ https://orcid.org/0000-0002-8151-4382
}

\section{Resumo}

Este trabalho compreende parte de uma pesquisa de dissertação e objetiva analisar o sentido atribuído pelos gestores escolares quanto à participação dos sujeitos nas escolas públicas estaduais do município de Assú/ RN. O problema deriva da seguinte questão: Qual o sentido de participação para os gestores escolares em tempos de gerencialismo? A abordagem da investigação é qualitativa, tendo como procedimento de construção de dados a pesquisa bibliográfica e o diário de pesquisa (BARBOSA, 2010). Como fundamentação teórica, amparamo-nos em Arendt (2011), Lima (2007), Frateschi (2007) e Barbosa (2010), dentre outros autores. A participação evita a tomada de decisões unilaterais e constitui exercício de liberdade política e desenvolvimento de uma cultura democrática.

Palavras-chave: Participação. Espaço escolar. Gestão Democrática. Gerencialismo.

\begin{abstract}
This work comprises part of a master dissertation research and it aims to analyze the meaning attributed by school managers regarding the participation of subjects in state public schools in the city of Assú / RN. The problem derived from the following question: what is the meaning of participation for school managers in times of managerialism? The research approach is qualitative, having as a data construction procedure a bibliographic research and the research diary (BARBOSA, 2010). As theoretical foundation, we are supported in Arendt (2011), Lima (2007), Frateschi (2007) and Barbosa (2010), among other authors. The participation avoids unilateral decision-making and the exercise of political freedom and the development of a democratic culture.
\end{abstract}

Keywords: Participation. School space. Democratic management. Managerialism.

\footnotetext{
Mestranda em Educação pela Universidade do Estado do Rio Grande do Norte (UERN). E-mail: mcffonseca@gmail.com

Professora da Universidade do Estado do Rio Grande do Norte. Mestre em Educação pela Universidade Federal do Espírito Santo. Doutora em Educação pela Universidade Federal de São Carlos. E-mail: arilene.medeiros@bol.com.br
} 


\section{Introdução}

Este trabalho compreende parte de nossa dissertação desenvolvida no Programa de Pós-Graduação em Educação - POSEDUC, da Universidade do Estado do Rio Grande do Norte - UERN, defendida na linha de pesquisa Políticas e Gestão da Educação. A pesquisa objetivou analisar a contribuição da natalidade política na atuação democrática de gestores de escolas públicas estaduais no município de Assú/RN, à luz das ideias de Hannah Arendt. Intentamos compreender como a natalidade política ${ }^{3}$ - ideia construída a partir do pensar arendtiano poderia influenciar na atuação democrática de gestores escolares em tempos de gerencialismo.

As escolas públicas estaduais situadas no território do Rio Grande do Norte (RN) têm suas gestões constituídas através de eleições diretas desde a década de 1990 e, nos últimos 10 anos, surgiu nesse mesmo espaço o gerencialismo. Essa relação entre gestão democrática e gerencialismo é estabelecida através de parcerias entre o público e o privado, da razão mercadológica e do poder do capital privado.

Na investigação, atentamo-nos a algumas percepções: a instalação do gerencialismo vem adquirindo forma e conquistando espaço, enquanto que a gestão democrática tenta sobreviver ao avanço dessa outra gestão; na prática, essas gerências se conflitam, tendo em vista que seus pressupostos caminham em sentidos contrários.

Para a dominação do capital sobre a gestão democrática, o gerencialismo tem utilizado dos princípios democráticos (diálogo, participação e decisão) como se fossem fundamentos seus, na tentativa de camuflar as reais intenções capitalistas. A participação tem sido um dos princípios que essa gestão mais cerceia, na tentativa de inibila nos espaços públicos democráticos institucionalizados - Lei de Diretrizes e Bases da Educação/ LDB 9394/1996 (Conselho Escolar e Projeto Político-Pedagógico) - e não institucionalizados - reuniões, fóruns e assembleias.

No nosso entendimento, a participação é um princípio caro para a gestão democrática, pois a materialização dessa forma de gestão no espaço escolar passou a ser sinônimo de gestão participativa. Desse modo, discuti-la é compreender que ela está em vias de construção e que as dificuldades institucionais decorrentes das políticas educacionais ensejadas no Estado do RN com empresas do setor privado terminam por coibi-la.

Por mais que a democratização das instituições educativas tenha avançado nos últimos anos - com a promulgação da Constituição Federal de 1988 e da Lei de Diretrizes e Bases da Educação Nacional (LDB 9394/1996) -, a defesa da gestão democrática do ensino público necessita fortalecer-se para mediar conflitos e possíveis consensos (MEDEIROS, 2007). Desse modo, é preciso que conheçamos a gestão democrática e o exercício de seus princípios (diálogo, participação, liberdade), de maneira a compreender a continuidade ou a ruptura entre o que se conhece e o que se pratica.

Compreendemos por gestão democrática a ação política realizada pelos homens em espaços públicos, por meio dos quais eles participam, dialogam e decidem pelo bem comum, valorizando os princípios básicos da vida.

No Estado do RN, a gestão democrática se efetiva desde a década de 1980, tornando-se oficial em 2005, com a Lei complementar Nº 290 (RIO GRANDE DO NORTE, 2005a), regulamentada pelo Decreto no 18.463/05 (RIO GRANDE DO NORTE, 2005b) e revogada em 2016, pela Lei Complementar no 585. Antes dessa oficialização, a gestão de ensino pública na rede estadual do RN experenciava a prática do clientelismo político. Por anos, a

\footnotetext{
${ }^{3} \mathrm{Na}$ obra $A$ Condição Humana, Arendt (2014) versa a natalidade como característica natural e fundamental do pensar político, associado à ação e também à liberdade. Sua maior referência é o surgimento de novos seres humanos, resultante da ação daqueles que os precedem. Por ser centrada em novos seres, gera a responsabilidade daqueles que os trazem ao mundo, devendo prepará-los para participar desse universo que estão a chegar, assim como conhecê-lo e preservá-lo para quem virá a posteriori.
} 
indicação de gestor e vice gestor das escolas públicas estaduais ocorria sob a forma de nomeação e associada a algum grupo político aliado ao governo estadual.

Isto posto, as mudanças na forma de provimento de cargo para gestor foram marcadas por progressos e retrocessos. As transições não aconteceram por vontade política dos administradores estaduais, mas pelas reivindicações de órgãos representativos de profissionais da Educação, como a exemplo a Associação Nacional de Política e Administração da Educação (ANPAE). Foi através do empenho de instituições como essa que a ocupação de cargos de gestores ocorreu democraticamente, isto é, por meio de eleição direta, com a participação da comunidade escolar.

Vale lembrar, também, que antes da Lei № 290/05 ocorreram no Estado duas experiências sob a forma de eleição direta para o provimento do cargo de gestor escolar: a primeira realizada em 1984, com apenas 03 (três) escolas $^{4}$ participantes; e a segunda em 1989, com a participação de 100 (cem) escolas, sendo 70 no interior do RN e 30 na capital do $\operatorname{Estado}^{5}$ (CABRAL NETO, 1995).

O processo da democratização da gestão escolar teve início em 2002, a partir do compromisso assinado pelo governo com as categorias dos educadores. Mas foi com a elaboração da Lei Complementar N ${ }^{\circ}$ 290/2005 que ocorreu a expansão da proposta de gestão democrática para todas as escolas da rede estadual de ensino, definindo a eleição direta como forma de escolha de dirigentes de escolas da Educação Básica no Estado do RN.

A gestão passou a ser exercida pela equipe da Gestão Escolar, com o auxílio e a físcalização do Conselho de Escola e sob a supervisão do secretário de Estado da Educação (RIO GRANDE DO NORTE, 2005a; 2016). Em 2016, a Secretaria de Educação do RN revalidou a Lei No 290/05, através da Lei Nº 585/2016, intencionando ampliar a gestão democrática e sua materialização no espaço escolar.

Diante desse contexto, problematizamos a seguinte questão: qual o sentido da participação para os gestores escolares em tempos de gerencialismo? No tocante à metodologia, a abordagem do estudo é qualitativa, tendo como procedimento de construção de dados a revisão bibliográfica e o diário de pesquisa (BARBOSA, 2010). Esse procedimento foi utilizado pelos gestores escolares - participantes da investigação -, no qual buscamos trabalhar a compreensão desses sujeitos sobre participação.

O diário de pesquisa suscita "um re-olhar sobre si mesmo no ato de andar, fazer, estar e ser" (BORBA apud BARBOSA, 2010, p. 13). Além disso, “[...] cria condições para oportunizar o que podemos denominar de aprendizagem existencial, aquela voltada para o aprendizado não somente de fórmulas ou pensamentos prontos, mas do processo de elaboração de si” (BARBOSA, 2010, p. 18). Ele viabiliza a busca pelo ser "de dentro e não de fora" (LAFER, 2007, p. 290), assim como sugere outros procedimentos (questionários, entrevistas, dentre outras). Corresponde à situação em que o sujeito fala de algo a partir de sua vivência, do espaço onde se constitui protagonista. Ademais, o diário foi fundamental para a construção deste trabalho, tendo em vista que constituiu a base metodológica que intentou ouvir e compreender o sujeito a partir do espaço de sua existência.

Inicialmente, o diário de pesquisa parte da escrita individual, com estilo livre e espontâneo, e, posteriormente, pública. A princípio, foi necessário ouvir e perceber o sentido e o sentimento dos participantes da pesquisa quando escolhemos utilizá-lo para que discorressem sobre o cotidiano de suas atividades. Os escritos foram obtidos a

\footnotetext{
${ }^{4}$ Colégio Estadual do Atheneu Norte-rio-grandense, Centro de Ensino Supletivo Felipe Guerra e Escola Estadual Professor José Fernandes Machado (CABRAL NETO, 1995).

${ }^{5}$ A maioria dos gestores não tiveram como finalizar os mandatos para os quais foram eleitos, por posicionarem-se a favor da categoria dos professores durante a greve deflagrada em 1990. O governo desmontou a experiência de eleições diretas e impediu a criação dos Conselhos Escolares, ou seja, a institucionalização de espaços públicos de exercício da democracia (CABRAL NETO, 1995).
} 
partir de dois gestores de escolas do Ensino Fundamental da rede pública estadual situadas na cidade de Assú/ RN, alcunhadas "Escola 01" e "Escola 02". Aos partícipes solicitamos que relatassem o cotidiano das atividades desempenhadas. Nas tessituras, encontramos respostas que denotam o pensar desses sujeitos, que apontam suas possíveis natalidades políticas, ignoradas, por vezes, pela pressa diária.

No que tange à base teórica, amparamo-nos em Arendt (2011), Lima (2007) e Frateschi (2007), que discutem o princípio da liberdade política, a participação na escola como princípio democrático e as ideias arendtianas, respectivamente.

\section{Da institucionalização à construção da participação no espaço escolar}

É praticamente impossível discutir participação sem que debatamos sobre democracia, entendida como a forma de governo em que a soberania popular é exercida pelo povo. No decorrer do tempo, o conceito de democracia transitou e também instituiu algumas modalidades. Dentre elas estão a democracia representativa (ou indireta) e a democracia participativa (ou direta). A diferença entre elas está no exercício do governo popular, no envolvimento desse público para com os contextos democráticos.

A democracia representativa tem como preceito a participação popular, ou seja, esse público elege os representantes para assumir as casas parlamentares e o poder no executivo. A esses representantes é permitido falar em nome dos representados que lhes outorgaram o poder de tomar decisões por eles. Esse tipo de democracia está mais próximo ao entendimento de política profissional ou política partidária e distante da compreensão arendtiana de política como liberdade (ARENDT, 2017). Já na democracia direta, a participação popular acontece coletivamente, isto é, as decisões e deliberações são dialogadas conjuntamente.

Partindo do pensar arendtiano, a democracia valorizada é a direta, que aproxima os sujeitos em espaço público e favorece o diálogo e a pluralidade de reflexões. Ao valorizá-la, Arendt (2011) crítica a ideia de democracia representativa e afirma que ela pode contribuir para a a-politização dos sujeitos, assim como para a formação de movimentos totalitários e da sociedade de massa ${ }^{6}$, constituída por aqueles que jamais haviam participado ou tinham interesse em participar da vida política e de debates nos espaços públicos.

Para Arendt (2011, apud FRATESCHI, 2017), o problema da representação é transformar a democracia em mera formalidade, constituindo uma democracia abstrata, carente de órgãos concretos de participação política e que permitam ao povo se envolver nas atividades de expressão, discussão e decisão.

Parece desconfortável tratar da a-politização dos sujeitos e sua contribuição aos movimentos totalitários, principalmente em sociedades democráticas, visto que no pensamento comum a democracia impediria o desenvolvimento desses movimentos. No entanto, estamos assistindo à materialização do processo. As democracias atuais são terrenos propícios para desenvolver marchas extremistas justamente por não conseguirem impedir a manifestação dos que se utilizam das divergências e daqueles que se servem de mecanismos institucionais para se manifestarem.

A democracia está vivendo uma crise, possivelmente motivada pela burocratização e pela perda de poder das instituições tradicionais, como a exemplo da família e da Igreja, o que caracteriza a perda de autoridade.

\footnotetext{
${ }_{6}$ Na sociedade de massa pensada por Arendt (2016), os sujeitos não se unem pela consciência de um interesse comum. A eles faltam determinação de objetivos; são pessoas politicamente avessas à participação direta.
} 
Consequente a isso, há a redução de espaços de liberdade por meio dos quais o sujeito, na condição de cidadão, não pode agir e se fazer ouvir, ou seja, ser cooperador em contribuir para a concretude do exercício democrático.

Adverse (2012), ao amparar-se no pensar de Arendt, expõe que nas democracias modernas o exercício da liberdade - sentido político arendtiano - fica restrito ao dia das eleições, e a atividade política limitada à ocupação de uma elite de profissionais políticos. Essa simples atividade, no nosso entendimento, não garante uma sociedade democrática, pois ela está permeada por movimentos totalitários. Esses movimentos trazem o desejo de dominação paulatinamente alcançados, através de mecanismos como a propaganda e a ideologia a eles veiculados. Diante disso, precisamos desafiar essa situação e acreditar que o que põe a democracia em movimento é a participação política dos sujeitos - e não a participação para a representatividade -, em emancipá-los por meio do diálogo e das decisões coletivas.

Segundo Marques (2009), a garantia de uma sociedade democrática está nos princípios da liberalização contestação pública das decisões governamentais, que pode ocorrer através do conflito e consensos nos espaços públicos - e inclusividade - participação nas decisões políticas na esfera pública.

Na obra Sobre a Revolução (2011), Arendt reflete sobre a participação, ao mencionar no seu estudo duas revoluções: a Revolução Americana (1776) e a Revolução Francesa (1789). A autora apresenta a primeira Revolução como a mais exitosa no alcance da liberdade política e tipificada sob dois argumentos: $1^{\circ}$ ) os americanos não tinham nenhuma questão social para resolver como, por exemplo, a pobreza ou a fome; $2^{\circ}$ ) a sociedade já tinha o costume de participar politicamente em assembleias locais e discutir pactos político-sociais. Entretanto, na sua compreensão, os americanos não foram além. Apesar de garantirem a liberdade política, eles falharam ao não criar espaços públicos para o exercício da liberdade e dos ideais democráticos (JARDIM, 2011).

Sobre essa Revolução, Frateschi (2017, p. 91) assenta:

[...] embora tivesse dado liberdade ao povo, não conseguiu proporcionar um espaço onde essa liberdade pudesse ser exercida: apenas os representantes, e não o próprio povo, tiveram uma oportunidade de se engajar nas atividades de expressão, discussão, decisão, as quais, num sentido positivo, são as atividades de liberdade.

No entendimento de Correia (2014), a Revolução Americana forneceu espaço público apenas para os representantes do povo, e não para o próprio povo. Segundo o autor, isso explica a razão de, nas democracias modernas, em geral, o exercício da liberdade política restringir-se ao dia das eleições e a atividade política ser desenvolvida ou exercida apenas por políticos profissionais.

O que podemos perceber diante desse contexto é que a representação tomou o lugar da ação, retirando do homem o acreditar na política como liberdade e instituindo a crença de que a política pertence a uma elite partidária. Essa elite, representante do povo, tem desenvolvido e demonstrado sua atuação a partir de interesses privados, ocasionando a desilusão com a política e a ação de participar dos espaços públicos de diálogos.

Segundo Mounk (2019, p. 16):

A desilusão do cidadão com a política é coisa antiga; hoje em dia, ele está cada vez mais inquieto, raivoso, até desdenhoso. Faz tempo que os sistemas partidários parecem paralisados; hoje, o populismo autoritário cresce no mundo todo [...]. Não é de hoje que os eleitores repudiam esse ou aquele partido, político ou governo; agora, muitos deles parecem estar fartos da democracia em si. 
Nesses registros, há duas justificativas arendtianas sobre a democracia representativa: a liberdade política significa o direito de ser participante no governo ou na gestão, e na democracia representativa a participação é reduzida ao ato de votar; a representação dá ênfase ao bem-estar individual do maior número de sujeitos, assim como o domínio da opinião comum impede o ressurgimento do espírito revolucionário, capaz de promover embates e resistências.

Em outra perspectiva, a democracia participativa é pautada na liberdade e na convivência da pluralidade e da singularidade, baseada na relação horizontal entre os sujeitos e no ouvir a voz do outro nos espaços públicos de atuação.

O que temos percebido nos últimos tempos é que essa desilusão quanto à participação não pertence apenas ao macro espaço, tem chegado, também, às pequenas instituições, como, a exemplo, as escolas. Essa situação é expressa nos escritos do diário de um dos gestores, ao apresentar os reveses para reunir a comunidade escolar:

\footnotetext{
Passamos por algumas dificuldades na escola quando tratamos de participação; [...] temos tido ausência de candidatos ao processo de eleição para a gestão escolar, o não-comparecimento às reuniões do Conselho Escolar, a carência de participação nos diálogos e decisões escolares (Diário do Gestor da Escola 2, 18 de abril de 2018).
}

Em vista disso, tudo leva a crer que estamos vivenciando uma "patologia" da participação expressa pelo alto índice de abstenção nos espaços públicos. A democracia escolar, que pode ser expressa através da gestão democrática, na participação das decisões da escola e que acreditávamos que estava em vias de estabilidade, parece estar sendo rejeitada, hostilizada e também em crise, principalmente nas escolas do RN, onde a presença do gerencialismo contraria todas as tentativas político-democráticas e parece se configurar como movimento totalitário escolar.

Na participação há a perspectiva de que o poder continue sendo constituído pelo povo ou pela comunidade escolar. O que estamos encontrando na escola é uma situação totalmente adversa e constituída pelos sujeitos da escola: a instalação do gerencialismo, a ausência de participação e a possível transformação do poder em poderviolência, já que as decisões no ambiente escolar passaram a ser de poucos e de forma unilateral.

Para Chanlat (2002, p. 02), a definição de gerencialismo corresponde a uma gestão que traz em si a "interpretação do mundo a partir das categorias da gestão privada", ou poderíamos dizer econômicas. O aspecto político na perspectiva arendtiana não se materializa nesse tipo de gestão. O que muito nos preocupa é a possibilidade do retorno do taylorismo na gestão da educação a partir de uma releitura, denominada neotaylorismo (LIMA, 2011).

A incorporação de aspectos neotayloristas na gestão seria o fator inovador que possivelmente levaria a gestão à modernidade, mantendo seu sentido, que é estabelecer relações com os mecanismos de controle e parâmetros econômicos e prejudicar os referenciais democráticos da instituição escolar, quebrando o pacto de democracia na escola.

Sobre esse contexto, Lima (2011) reflete acerca do processo de democratização e participação inserido no ambiente escolar. Inicialmente, ele aponta que a "participação é hoje uma palavra-chave omnipresente nos discursos político, normativo e pedagógico" (LIMA, 2011, p. 69), mesmo que nem sempre se efetive como ato concreto de participação direta, a constituir-se como princípio democrático consagrado pelo mais alto nível normativo: a Constituição Federal de 1988, e depois pela LDB No 9.394/1996. 
A participação no espaço escolar passou por diversos processos: “[...] transitou do domínio da reivindicação para o da consagração e deste para ao da regulação; da legitimidade, de direito reclamado para um direito instituído e, até, para um dever ética e civicamente justificado" (LIMA, 2011, p. 71).

A instituição desse princípio na escola não ocorreu de forma pacífica e horizontalizada. Foi preciso, inicialmente, que inúmeros embates acontecessem para que o ato de participar fosse reconhecido como direito do sujeito. Um dos primeiros esforços foi a instituição educativa para o ato de participar, de construir espaços públicos para que a participação ocorresse/ocorra.

Com a instauração da gestão democrática nas escolas, a participação da comunidade escolar foi radicada em um quadro de valores que nem sempre era consensual sua vivência: "participar é um direito reclamado e conquistado através da afirmação de certos valores (democráticos) e da negação de outros que estiveram na base de uma situação de não participação forçada, ou imposta" (LIMA, 2011, p. 70).

Quando a participação é orientada pelo critério de democraticidade, ela representa uma forma de limitar certos tipos de poder e superar algumas formas de governo, garantindo, assim, a expressão de diferentes interesses e projetos com circulação na organização e a sua concorrência democrática em termos de influência na tomada de decisões.

O gerencialismo não compreende o sentido de política a partir das relações entre os homens nos espaços públicos, mas de forma inteiramente instrumental. Quando isso acontece, é possível que a política se corrompa, deixe de ser concentrada em uma atividade para o povo e seu bem-estar social, passando a se desenvolver como serviços de interesses privados - negociação própria, manobras políticas - e modificando o próprio estatuto da política, colocando-nos frente ao poder-violência. Isso se faz com o patrocínio do capital.

Esse aspecto pode inibir o princípio da participação e desenvolver na comunidade escolar a passividade, assim como a apatia ou o renunciar ao exercício desse princípio nos espaços públicos. Desde que o sujeito compreendeu a perda da dignidade da política, esse tipo de comportamento tem sido percebido (TORRES, 2007). Nas nossas escolas, encontramos indivíduos que não querem participar ou não conseguem participar, por não reconhecerem mais utilidade ou propósito na política, ou, ainda, por não se reconhecerem como sujeitos políticos. O que eles não percebem são que suas atitudes permitirão um dos maiores flagelos da sociedade moderna, que é a formação da sociedade de massa e a instalação de movimentos autoritários.

Isso nos permite perceber a dificuldade de instaurar a democracia participativa em uma sociedade capitalista, cujas escolas são permeadas pelo o gerencialismo, que determina a manutenção e a reprodução dos interesses privados, incompatibilizando-se com a gestão participativa. A gestão democrática é um devir histórico e carece de projetos educacionais alternativos diante dos que estão postos na atualidade.

Quem participa avança na compreensão de política, toca a possibilidade de diálogo e o bem comum, o que assenta o pensar arendtiano, ao apresentá-lo como algo humano em um mundo pautado pela pluralidade e habitual a todos os homens.

O eixo da participação é, portanto, essencial, pois apresenta o indivíduo para o outro, mostrando e reafirmando sua singularidade, isto é, o falar, ser visto e ouvido nas discussões e deliberações da gestão escolar. Quanto ao âmago do diálogo, esse ato acontecerá pela condição da singularidade compreendida por cada sujeito, e isso pode reafirmar a pluralidade que constitui fundamentalmente a política e o eixo do bem comum. 
Assim, para compreender o caráter democrático da instituição escolar, faz-se necessário perceber que ela tem papel político. A política pensada por Arendt (2017) para esse contexto é compreendida como espaço de singularidades e pluralidades ao mesmo tempo. Precisamos, pois, entender a relação entre a educação emancipadora e a gestão democrática da escola, tendo claro que é impossível fazê-la dogmaticamente. Também é ilusório pensála sem a participação de pais e alunos, limitada tão somente aos servidores da escola.

\section{Participação e liberdade política}

O gerencialismo instituído nas escolas como forma de gestão tende a limitar a esperança de emancipação e inibir ou prejudicar os espaços públicos para evitar a participação dos sujeitos partícipes da/na escola. Desse modo, há um sério risco de reprimir a liberdade política e interromper os processos democráticos (MOUNK, 2019).

Essa liberdade política também sofre por outras situações: os ataques da direita populista e da esquerda conservadora; a dúvida da capacidade de o homem comum compreender a política; o Estado do bem-estar social que mantém a liberdade pública como privilégio da minoria; o surgimento cada vez mais corrente da sociedade de massa e consumista pelo sistema partidário que termina por construir uma elite política; e a forma representativa do governo que exclui a maioria da política.

A liberdade política é pensada por Arendt (2011) como o direito à participação política, o que "[...] significa o direito de ser participante no governo, afora isso, não é nada" (ARENDT, 2011, p. 278). Sendo assim, não compreendemos a liberdade política como oportunidade dada aos sujeitos, mas como direito conquistado por meio de inúmeras lutas.

Embora essas observações sejam realizadas no contexto da contemporaneidade, nos é permissível enunciar que vivemos tempos sombrios para o próprio exercício da democracia, ou seja, subsistimos em um desequilíbrio na democracia, uma incerteza na república; estamos vivendo um tempo de desilusão e de ataque democrático, e percebemos quando encontramos "déspotas eleitos [...] transformando democracias incipientes em ditaduras eleitorais (MOUNK, 2019, p. 16) e espaços de liberdades em zonas de movimentos totalitários.

Essa realidade não vai apenas encarcerar a participação, mas segregar a possibilidade da natalidade política se efetivar e tornar real "o começo de uma nova história, iniciada por homens de ação" (ARENDT, 2011, p. 78) que compreendem o que seja política, espaço público e liberdade, conceitos caros para Arendt (2011 apud FRATESCHI, 2017).

Quando falamos do espaço escolar e da participação da comunidade escolar, nos remetemos de imediato à experiência de participação em processos eleitorais, em espaços públicos, como os Conselhos. Desses contextos democráticos, percebemos que esses órgãos expressariam a mais válida experiência da liberdade pela participação na decisão dos assuntos públicos e sua inexistência fragilizaria uma organização política dita democrática (TORRES, 2007). Logo, esses colegiados se constituem como espaços de liberdade.

Pensar na experiência dos Conselhos como garantia de liberdade e exercício no espaço público permite-nos perceber que quem nele está se propõe a participar, debater e querer que suas vozes sejam ouvidas para determinar o destino ou os caminhos do curso político de suas histórias. Esses órgãos deliberativos são eventos que desvelam o desejo de liberdade política (FRATESCHI, 2017). 
Todavia, em um sistema político de representatividade, em que a participação e a cidadania são praticamente reduzidas ao ato de voto, a liberdade política é constantemente frustrada. O gerencialismo trabalha para que o fracasso da gestão democrática aconteça, pois inibe a criação e a manutenção do espaço público, da participação e das pequenas revoluções surgidas através do debate e do ouvir e ser ouvido.

A partir das ideias de Arendt (2011), a instituição do espaço público, como os conselhos, suscita a esperança de outra forma de gestão escolar que permita a cada membro tornar-se "participante" nos assuntos públicos. Isso não quer dizer que esses colegiados assumam a função de gestão, mas que as questões da instituição educativa sejam compartilhadas em um espaço que respeita o direito de opinar sobre as possíveis soluções. A intensão é oportunizar a participação e desnaturalizar o modo burocrático e elitista pelo que organizamos politicamente as escolas e a sociedade que se constituem por meio de democracias representativas.

O conflito entre gestão democrática e gerencialismo tem ocorrido envolto a inúmeros princípios, mas a participação tem sido um dos mais eupáticos nessa disputa. A manipulação do gerencialismo na redução drástica do espaço público tem sido constante. Nas entrelinhas desse contexto, não está apenas o prejuízo de participar, mas a exclusão da maioria dos processos decisórios, o prejuízo ao debate público e à formação conjunta da opinião.

Enquanto gestão escolar, o gerencialismo tende, de um lado, cada vez mais a restringir as vozes, a pluralidade, a liberdade e a igualdade política e, de outro, a favorecer uma minoria de sujeitos que talvez não tenha nenhuma vinculação com a instituição, como é o caso das organizações de capital privado, que têm incentivado a materialidade dessa forma de gestão em detrimento da comunidade escolar, isto é, do povo que está na escola, da gestão democrática.

Essa forma de gestão passa a concentrar poder nas mãos de poucos - de empresários, de um mercado de capital privado - que parcamente dialogam com a escola para compreender suas necessidades. As principais negociações limitam-se às secretarias e diretorias de Educação e aos representantes políticos, que instituem manobras políticopartidárias e contratos acertados para enviar pacotes salvacionistas para as escolas.

Essa realidade é registrada pelo Gestor da Escola 2 no seu diário:

Com toda sinceridade, eu vejo com preocupação. [...] preocupação no sentido de que esse gerenciamento todo, na realidade, traz para as escolas pacotes administrativos baseados no pensamento de grandes instituições. Assim, muitas delas não estão nem preocupadas no ensino-aprendizagem. Estão [...] preocupadas no mercado da educação brasileira, no mercado e na possibilidade de ser privatizado (Diário do Gestor da Escola 2, 15 de junho de 2018).

Essa atuação e negociação restrita aos órgãos diretivos impede a participação da comunidade escolar nas decisões educativas, postergando-a de colaborar e delimitando-a à tarefa de aplicar as propostas das quais não participou. Para Arendt (2011), isso não passa de uma imitação sem sentido, de um pseudo diálogo entre as empresas de capital privado e a microestrutura educativa (escola) através da macroestrutura (diretoria e secretarias).

Uma das tentativas de evitar essa situação tem sido fortalecer a gestão democrática vivenciada no cotidiano das escolas, ampliando os espaços de participação para que a liberdade política encontre lugares de sobrevivência e resistência. Desse modo, precisamos de espaços concretos para deixar que o desejo de participação e debate se materializem, por via da formação conjunta de opinião, assim como da instituição de poder que nasce quando os homens decidem se organizar, se unir na perspectiva de estabelecer o diálogo; de experiências concretas sobre o exercício da democracia, menos excludentes e mais condizentes com o exercício do poder. 
Esse poder emerge quando os homens se unem com o objetivo de agir livre da dominação. Para Arendt (2011), o potencial democrático está no estabelecimento das relações políticas baseadas na igualdade e reciprocidade, que fogem à lógica tradicional e oligárquica da relação entre representantes e representados. A democracia se constrói com procedimentos e instituições condizentes com o direito à participação.

Compreendemos, também, que nem todos os que compõem a comunidade escolar têm interesse por assuntos políticos. Segundo Arendt (2014), a democracia pode caminhar bem, mesmo que parte da população renuncie à política. Todavia, ela estará comprometida se o direito e a oportunidade de participar não forem construídos para todos. A exigência arendtiana de que a participação seja um direito está em conformidade com a noção de igualdade política, que é definida como princípio regulador da organização política, segundo o qual pessoas distintas têm direitos iguais. Portanto, democracia passa necessariamente pela ampliação de participação política, como direito de todos os cidadãos.

\section{Diário de pesquisa do gestor escolar e sua compreensão sobre participação}

O uso do diário de pesquisa como procedimento de construção de dados foi utilizado para que pudéssemos compreender o gestor em seu espaço de atuação, de maneira que suas percepções viessem à tona, tornando o sentido da participação o foco central de nossas discussões nesse item. Esse instrumento permitiu horizontalizar as relações entre a pesquisadora e os pesquisados.

Com Arendt (1992), percebemos que esse modo de constituir a ciência tem significativa contribuição, entendendo a forma que se concebe o autor do que está escrito e, ao mesmo tempo, sabendo que o sujeito foi formado a partir das experiências adicionadas à sua existência. Essa maneira de construir o conhecimento distanciase dos procedimentos que "busca dar a voz" ao indivíduo (questionários) e representa um dos grandes fracassos da modernidade, uma vez que o ato de pensar requer um olhar de quem age e discute, seja de dentro para fora e não o inverso.

O diário de pesquisa foi apresentado aos gestores escolares para que descrevessem suas atividades e compreensões, buscando enxergar os "andaimes" do seu pensar e agir. Para Barbosa (2010), o termo andaimes tem importante significado no diário de pesquisa, pois configura-se como aspectos da construção de si. Foi no entendimento desse autor que nos pautamos para explicar aos gestores que seu pensar, agir e ser são constituintes de sua forma de gerir uma instituição escolar.

Assim, o diário de pesquisa apresentou o andaime que nos deu as pistas, isto é, revelou a compreensão sobre a participação política da/na comunidade escolar, assim como nos possibilitou perceber como acontece a ação nos espaços de liberdade, quando e por que acontece. Os gestores puderam descrever o exercício de suas gestões, o pensar sobre si sob a forma de escrita particular; permitiu o agir sobre a pesquisadora, que se utilizou dos registros para desenvolver a tradução e a interpretação do material, construindo-se também no processo. Gestor e pesquisadora se intercomunicaram no espaço do diário e cresceram mutuamente na condição do pensar.

Esse instrumento possibilitou aos participantes pensar e possivelmente apresentar sentidos às suas observações, como: o sentido de participação; os desafios que a escola enfrenta com a ausência dessa participação; a escola como instituição capaz de promover processos emancipatórios e possibilitar a liberdade dos sujeitos. 
Portanto, os escritos não pertenceram a alguém que esteve na escola, que observou e perguntou, são palavras, sentimentos e intenções de quem nela protagonizou e se tornou experiência.

Os escritos caracterizaram verdadeiros registros do cotidiano dos gestores, mesmo que inibidos e rígidos, inicialmente. Identificamos os relatos da compreensão dos sujeitos sobre suas atividades na gestão como: a gestão democrática e a submissão das possiblidades tecnicistas desenvolvidas pela introdução do gerencialismo; as obscuridades dos conceitos democráticos; a ausência do aspecto político na sua compreensão à pouca participação dos pares.

Esses apontamentos ficaram visíveis no diário de pesquisa do gestor 02, ao expressar sua preocupação com a gestão democrática que vem se materializando na escola:

[...] meu trabalho começou com os funcionários, iniciei reunindo eles. Para mim, era essencial que todos entendessem que para qualquer coisa acontecer na escola o papel de cada um é fundamental. $\mathrm{Na}$ educação temos mais que uma função, cada um de nós tem uma missão. Precisava resgatar essa estima para poder contar com cada funcionário na minha gestão. Não importa o que faz, importa o que façamos, todos olhando na mesma direção, todos podem e devem participar (Diário do Gestor da Escola 2, 02 de maio de 2018).

Esse discurso permite-nos entender que gestor é ciente da importância do exercício da democracia no espaço escolar e que sua materialização acontece nos espaços públicos escolares. O participante também trata da importância de resgatar a participação para as tomadas de decisões. Nesse mesmo fragmento, atentamos à seguinte colocação: [...] não importa o que faz, importa o que façamos, todos olhando na mesma direção. A partir desse trecho, inferimos que o gestor não acredita em uma homogeneidade de opinião, mas considera possível o diálogo e a temporária ação conjunta, levando-nos a entender que participação é fundamental e que cada um tem seu papel. A participação não se trata de uma construção unilateral, mas coletiva. Participar tem relação com a autoestima, sem esta há o esvaziamento da participação.

É na aparição no espaço público e na capacidade de manter o diálogo que o ideal de fala acontece, de se expressar em uma reciprocidade igualitária, admitindo que todos os participantes têm chances iguais de iniciar, continuar, contribuir com os desejos e sentimentos, assim como devem ser livres para tematizar. Dessa forma, estamos em uma tentativa de impedir que a experiência de participação na escola seja reduzida a um meio, configurado como mera adaptação funcional dos indivíduos às situações do cotidiano, vivenciadas sem um mínimo de reflexão e isolados de seus pares.

Quando tratamos de participar não restringimos apenas à comunidade escolar interna, mas a todos os que fazem parte da escola: professores, alunos, gestor, pais. No entanto, parece que a patologia da participação também atingiu a comunidade externa, como os pais. Estes têm pouco chegado à escola, sendo uma das grandes dificuldades enfrentadas no cotidiano da instituição, como observamos no diário do gestor da Escola $\mathrm{n}^{\mathrm{o}} 01$ :

[...] os pais têm pouco chegado a escola. É preciso convocar não apenas uma vez, mas diversas. Nas reuniões para resultados bimestrais, os pais não podem, sempre há uma justificativa para não comparecerem. Essas reuniões têm sido esvaziadas os últimos tempos (Diário do Gestor Escolar 1, 15 de junho de 2018).

A ausência dos pais na escola indica um desafio para a comunidade escolar, pois fragiliza a participação na instituição. As decisões que poderiam ser tomadas conjuntamente, beneficiando a todos, acaba por confirmar 
uma decisão unilateral tomada e assumida apenas por quem está na escola. Essa situação põe em risco os espaços de atuação democrática como, por exemplo, a atuação do Conselho. Essa ausência possibilita que movimentos totalitários, como o gerencialismo, se instale na escola, pois uma das forças de resistência contra essa gestão está inativa pela inexistência de participação.

Diante disso, precisamos entender que a escola não pertence apenas ao estudante, professor e outros sujeitos que trabalham nesse ambiente, mas a todos que estão inseridos no seu contexto. Seu caráter emancipatório tem como objetivo desenvolver a liberdade no mundo e a consciência de si mesmo.

Não há, pois, uma consciência no isolamento, apartado da pluralidade dos homens que habitam o mundo comum, mas, antes, a formação de um ser singular que se constitui por meio de sua relação com a humanidade e sua história. Esse contexto é expresso pelo gestor da Escola 01:

[...] às vezes acho que não estamos fazendo o trabalho certo. Os pais acreditam que o nosso papel é apenas ensinar a escrever, ler e contar. Ensinando essas três funções tudo está resolvido. Mas esquecem que formamos para um mundo de diferenças, de pessoas diferentes (Diário do Gestor da Escola 1, 04 de junho de 2018).

É perceptível que o gestor se preocupa para além das atividades básicas desenvolvidas pela escola, como também é ciente da responsabilidade dos pais com a formação emancipatória dos filhos. Isso porque compreende que o projeto educativo é maior do que as atividades instrumentais, pois apresentar as responsabilidades que os adultos precisam ter com os estudantes em formação constitui responsabilidade pelo mundo (ARENDT, 2016).

O principal sentido que a participação assume nos diários dos gestores escolares é pensá-la como antídoto à burocratização, à instalação do poder-violência - que não considera a institucionalidade do diálogo - e aos movimentos totalitários - que negam a pluralidade e a dignidade humana. O gerencialismo faz isso porque seu movimento não é o do reconhecimento do outro como autor de opiniões e decisões. Pelo que vimos nos registros dos representantes escolares, é atribuir um sentido de participação mais próximo dos pressupostos arendtianos, que trata da liberdade, do que gerenciais, que apresenta um processo de dominação e doutrinação.

\section{Considerações finais}

A democracia experencia uma crise. São tempos sombrios para o exercício da soberania popular. Como resultado dessa crise, duas situações têm se concretizado: a perda ou a diminuição dos espaços de liberdade (públicos) e a instalação do poder-violência. Isso tem impedido a concretude de nossa capacidade de agir como sujeitos políticos, de ação.

Essa ação ocorre pela capacidade de o indivíduo participar em espaço de liberdade, ou seja, precisamos garantir a existência desses espaços para que a democracia possa se materializar, de maneira que nossas vozes sejam ouvidas e percebidas por aqueles que nos representam. Entretanto, o que temos assistido é a redução desses locais e a patologia da participação, configurada sob a forma de reclusão, recusa de agir e participar da esfera pública. Essa realidade tem provocado preocupação, pois seria normal esse acontecimento em situações extremas, como no caso dos regimes autoritários ou totalitários, mas pouco ou quase incomum em sistemas republicanos. 
Quando traduzido para a escola, temos visto a mesma situação: essa instituição educativa parece ser formada apenas pela comunidade interna e os pais pouco têm chegado a ela, caracterizando problema de participação escolar. $\mathrm{O}$ afastamento da comunidade externa que também compõe a escola e a ausência de sua participação como força de resistência aos movimentos totalitários têm fragilizado os conflitos de resistências e permitido que o gerencialismo institua-se no espaço escolar, assim como compartilhe lugar com a gestão democrática, avançado significativamente a materialização de sua gestão. O pacto entre democracia e escola tem se fragilizado, as atividades políticas têm se reduzido a meras formalidades, permitindo que a persuasão, a negociação e o acordo sejam atividades raras no ambiente escolar.

Quando Arendt (2011) crítica a representatividade, a autora não coloca em pauta que essa concepção precise ser substituída pela participação direta. Sua maior preocupação é a perda dos processos democráticos e dos princípios vinculados à ausência da política como sentido de liberdade e instalação de uma política profissional formada por uma elite partidária. É preciso, pois, refazer toda a trajetória democrática, de maneira a não abolir o sistema de representatividade como algo inútil, mas reformá-lo para que os interesses da coletividade sejam prioridade; que a garantia do direito aos que estão fora do sistema seja garantida, assim como ganhos à possibilidade da ação e formação constante do poder.

Posto isso, se queremos que a participação aconteça, precisamos garantir os espaços de liberdade. Um exemplo prático dessa prerrogativa é a institucionalização dos Conselhos, de modo que a comunidade externa que congrega esse órgão deliberativo possa discutir as fragilidades que ocorrem no espaço da escola e clarificar as medidas adotadas, ou a serem adotarem, para os problemas que estão postos. É válido esclarecer que esse colegiado não pode ser vislumbrado como órgão administrativo, com papel e função de gestor, mas compreendido como espaço de liberdade, ação e participação efetiva dos sujeitos, assim como os pontos pleiteados nas pautas de reuniões necessitam se concretizar, de maneira a diminuir as vulnerabilidades que ocorrem no contexto escolar. É nesse aspecto que o pensamos instituído na escola, como espaço de liberdade política para todos que dela participam, compartilhando o poder na instituição e tornando-se responsáveis pela sua vivência.

Consideramos que a participação é um princípio necessário acertado para que os que fazem parte e fazem a escola, mesmo com a existência de uma gestão que persiste em erradicá-lo obstinadamente, como é o caso do gerencialismo. Entretanto, é preciso que os sujeitos que vivenciam esse contexto não se reprimam ou desistam de lutar pelos espaços onde suas vozes devem fazer e ser a diferença pela mudança, mas que se legitimem enquanto sujeitos políticos, de ação, isto é, que não silenciem ou sejam cerceados verticalmente por aqueles a quem demos poder de ação de nos representarem. Precisamos exercer a cidadania, que é exercida quando as vozes, coletivamente, são ouvidas e percebidas na construção de uma sociedade melhor, incluído aqui, também, o espaço escolar, espaço este não somente de replicação de aprendizado, mas ambiente onde devemos nos construir pelo pensamento e também pela ação, não desconsiderando as funções básicas da escola (ler, escrever, contar e tantas outras).

\section{Referências}

ADVERSE, H. Arendt, a democracia e a desobediência civil. Revista Brasileira de Estudos

Políticos. Belo Horizonte, n. 105, p. 409-434, jul/dez, 2012. 
ARENDT, H. A vida do espírito: o pensar, o querer, o julgar. Rio de Janeiro: Relume-Dumará, 1992.

ARENDT, H. Sobre a revolução. Tradução de Denise Bottmann. São Paulo: Companhia das Letras, 2011.

ARENDT, H. A condição humana. Tradução Margaret Canovan. Rio de Janeiro: Forense Universitária, 2014.

ARENDT, H. A promessa da política. Tradução de Pedro Jorgensen Jr. Rio de Janeiro: DIFEL, 2016.

ARENDT, H. O que é política? Tradução de Reinaldo Guarany. 12. ed. Rio de Janeiro: Bertrand Brasil, 2017.

BRASIL Constituição da República Federativa do Brasil de 1988. Disponível em: http://www. planalto.gov.br/ccivil_03/constituicao/constituicaocompilado.htm. Acesso em: 20 out. 2019.

BRASIL. Lei N. ${ }^{\circ}$ 9.394, de 20 dezembro de 1996. Estabelece as diretrizes e bases da educação nacional. Disponível em: http:/www2.camara.leg.br/legin/fed/lei/1996/lei-9394-20-dezembro-1996362578-publicacaooriginal-1-pl.html. Acesso em: 20 out. 2019.

BARBOSA, J. G.; HESS, R. O Diário de Pesquisa: o estudante universitário e seu processo formativo. Brasília: Liber Livro, 2010.

CABRAL NETO, A. Democratização da educação no Projeto Nordeste e seus desdobramentos no Rio Grande do Norte: memória reconstruída. 1995. 187f. Tese (Doutorado em Educação) - Faculdade de Educação da Universidade de São Paulo, São Paulo, 1995.

CHANLAT, J. F. O gerencialismo e a ética do bem-comum: a questão da motivação para o trabalho nos serviços públicos. In: VII Congreso Internacional del CLAD sobre la Reforma del Estado y de la Administración Pública. Anais [...]. Lisboa, Portugal, 2002, p. 1-9. Disponível em: http://unpan1. un.org/intradoc/groups/public/documents/clad/clad0043316.pdf. Acesso em: 05 out. 2019.

CORREIA, A. Hannah Arendt e a modernidade: política, economia e a disputa por uma fronteira. Rio de Janeiro: Forense Universitária, 2014.

FRATESCHI, Y. Participação e liberdade política em Hannah Arendt. Cadernos de Filosofia Alemã. São Paulo, n. 10, p. 83-100, jul/dez, 2007.

FRATESCHI, Y. Liberdade política e cultura democrática em Hannah Arendt. Cadernos de Filosofia Alemã. São Paulo, n. 03, p. 29-50, jul/dez, 2017.

JARDIM, E. Resenha de 'Sobre a revolução', de Hannah Arendt. O Globo, Rio de Janeiro, 21 set, 2011. Disponível em http://blogs.oglobo.globo.com/prosa/post/resenha-de-sobre-revolucao-de-hannaharendt-381674.html. Acesso em 30 set. 2019.

LAFER, C. Experiência, ação e narrativa: reflexões sobre um curso de Hannah Arendt. Estudos Avançados. São Paulo. v. 21, n. 60, p 289-304, mai/ago, 2007. Disponível em: http://www.scielo.br/ pdf/ea/v21n60/a22v2160.pdf. Acesso em: 05 out. 2019. 
LIMA, L. A deliberação democrática nas escolas: os procedimentos gerenciais e as decisões políticas. In: SANCHES, M. F. C. (Org.). Cidadania e liderança escolar. Porto: Porto Editora, 2007, p. 39-55.

LIMA, L. C. A escola como organização educativa: uma abordagem sociológica. São Paulo: Cortez, 2011.

MARQUES, V. T. Conselhos municipais de educação e democracia: relações entre Estado e Sociedade nos Conselhos Municipais de Educação em Sergipe. 190f. Tese (Doutorado) Universidade Federal da Bahia, Salvador, Programa de Pós-Graduação em Ciências Sociais, 2009.

MEDEIROS, A. M. S. Administração educacional e racionalidade: o desafio pedagógico. Ijuí: Unijuí, 2007.

MOUNK, Y. O povo contra a democracia: por que nossa liberdade corre perigo e como salvá-la. Tradução Cássio de Arantes Leite e Débora Landsberg. São Paulo: Companhia das Letras, 2019.

RIO GRANDE DO NORTE. Lei Complementar N. ${ }^{\circ}$ 290, de 16 de fevereiro de 2005 - Dispõe sobre a democratização da gestão escolar no âmbito da rede pública estadual de ensino do Rio Grande do Norte e dá outras providências. Disponível em: http://adcon.rn.gov.br/ACERVO/gac/DOC/ DOC000000000067614.PDF. Acesso em: 30 ago. 2019.

RIO GRANDE DO NORTE. Decreto $\mathbf{N}^{\circ} 1 \wedge, \leq 4$, de 24 de agosto 2005 - Regulamenta a Lei Complementar Estadual n. ${ }^{\circ} 290$, de 16 de fevereiro de 2005, que dispõe sobre a democratização da gestão escolar no âmbito da Rede Pública Estadual de Ensino do Rio Grande do Norte. DOE $\mathrm{n}^{\mathrm{o}}$ 11.055, de 26de agosto de 2005, p. 1-2. Natal, 2005. Disponível em: http://portal.mec.gov.br/seb/ arquivos/pdf/Consescol/rn_est.pdf. Acesso em 30 ago. 2019.

RIO GRANDE DO NORTE. Lei Complementar N. ${ }^{\circ}$ 585, de 30 de dezembro de 2016 - Dispõe sobre a Gestão Democrática e Participativa da Rede Pública Estadual de Ensino do Rio Grande do Norte e dá outras providências. Disponível em: http://adcon.rn.gov.br/ACERVO/gac/DOC/ DOC000000000137417.PDF. Acesso em: 02 out. 2019.

TORRES, A. P. R. O sentido da política em Hannah Arendt. Revista Trans/Form/Ação, São Paulo, v. 30, n. 2, p. 235-246, 2007. 